\title{
Particulate Air Pollution, Ambulatory Heart Rate Variability, and Cardiac Arrhythmia in Retirement Community Residents with Coronary Artery Disease
}

\author{
Scott M. Bartell, ${ }^{1,2,3}$ John Longhurst, ${ }^{4,5}$ Thomas Tjoa, $^{3}$ Constantinos Sioutas, ${ }^{6}$ and Ralph J. Delfino ${ }^{3}$
}

${ }^{1}$ Program in Public Health, and ${ }^{2}$ Department of Statistics, University of California, Irvine, Irvine, California, USA; ${ }^{3}$ Department of Epidemiology, ${ }^{4}$ Susan Samueli Center for Integrative Medicine, and ${ }^{5}$ Cardiology Division, Department of Medicine, School of Medicine, University of California, Irvine, Irvine, California, USA; ${ }^{6}$ Department of Civil and Environmental Engineering, Viterbi School of Engineering, University of Southern California, Los Angeles, California, USA

BACKGROUND: Decreased heart rate variability (HRV) has been associated with future cardiac morbidity and mortality and is often used as a marker of altered cardiac autonomic balance in studies of health effects of airborne particulate matter. Fewer studies have evaluated associations between air pollutants and cardiac arrhythmia.

OвJECTIVES: We examined relationships between cardiac arrhythmias, HRV, and exposures to airborne particulate matter.

METHODS: We measured HRV and arrhythmia with ambulatory electrocardiograms in a cohort panel study for up to $235 \mathrm{hr}$ per participant among 50 nonsmokers with coronary artery disease who were $\geq 71$ years of age and living in four retirement communities in the Los Angeles, California, Air Basin. Exposures included hourly outdoor gases, hourly traffic-related and secondary organic aerosol markers, and daily size-fractionated particle mass. We used repeated measures analyses, adjusting for actigraph-derived physical activity and heart rate, temperature, day of week, season, and community location.

RESULTS: Ventricular tachycardia was significantly increased in association with increases in markers of traffic-related particles, secondary organic carbon, and ozone. Few consistent associations were observed for supraventricular tachycardia. Particulates were significantly associated with decreased ambulatory HRV only in the 20 participants using ACE (angiotensin I-converting enzyme) inhibitors.

CoNCLUSIONS: Although these data support the hypothesis that particulate exposures may increase the risk of ventricular tachycardia for elderly people with coronary artery disease, HRV was not associated with exposure in most of our participants. These results are consistent with previous findings in this cohort for systemic inflammation, blood pressure, and ST segment depression.

Citation: Bartell SM, Longhurst J, Tjoa T, Sioutas C, Delfino RJ. 2013. Particulate air pollution, ambulatory heart rate variability, and cardiac arrhythmia in retirement community residents with coronary artery disease. Environ Health Perspect 121:1135-1141; http://dx.doi. org/10.1289/ehp.1205914

\section{Introduction}

Decreased heart rate variability (HRV) has been associated with cardiac morbidity and mortality and is often used as a marker of autonomic dysfunction in the assessment of the impact of air pollution on cardiac autonomic control (Link and Dockery 2010). Associations also have been found between HRV and ischemia in coronary artery disease $(\mathrm{CAD})$ patients who are monitored by ambulatory electrocardiograms (ECGs), including findings of asymptomatic ST segment depression indicative of cardiac ischemia (Vardas et al. 1996). Given that many patients with CAD already have decreased HRV, pollutant exposures that lead to further HRV decreases might be expected to precipitate adverse clinical events such as ventricular tachycardia and myocardial ischemia and infarction. Indeed, a number of recent air pollution studies have focused on CAD patients, although with mixed findings regarding associations between air pollutants and HRV (Barclay et al. 2009; Folino et al. 2009; Hampel et al. 2010; Schneider et al. 2010; Zanobetti et al. 2010). Nevertheless, in a recent review of the literature on particulate

air pollution and cardiovascular outcomes, Brook et al. (2010) concluded that there was strong epidemiological evidence for an association between decreased HRV and shortterm exposures to particulate matter (PM) air pollution in various populations, with the most consistent findings in older or clinically susceptible populations.

In contrast, Brook et al. (2010) also concluded that there was limited or weak epidemiological evidence for associations of cardiac arrhythmia with short-term exposures to PM. In another review, Link and Dockery (2010) suggested that there was evidence of an association of PM with cardiac arrhythmias, particularly ventricular arrhythmias, in patients with underlying cardiac disease. Studies published since those reviews had mixed results: He et al. (2011) reported a significant association between personal $\mathrm{PM}_{2.5}$ (PM with an aerodynamic diameter of $\leq 2.5 \mu \mathrm{m}$ ) exposure and premature ventricular contractions among 105 middle-aged participants using ambulatory ECGs, but only among participants without cardiovascular disease, and Mills et al.
HRV effects in a randomized trial of dilute diesel exhaust exposure with 52 middle-aged participants. Little is known about possible mechanisms for PM effects on arrhythmia, although altered HRV, repolarization abnormalities, oxidative stress, and myocardial ischemia have been proposed as contributing factors (Link and Dockery 2010).

Between 2005 and 2007 we conducted a cohort panel study of acute cardiovascular outcomes with home-based ambient air pollution monitoring in the Los Angeles, California, Air Basin, where ambient air pollution is dominated by mobile sources. Our focus was on traffic-related ultrafine particles, which are particularly high in redox-active chemical components (Ayres et al. 2008; Verma et al. 2009) that are hypothesized to induce arrhythmias via lipid peroxidation, endothelial dysfunction, and other mechanisms involving oxidative stress (Griendling and FitzGerald 2003). In the present study, we used data from the same Los Angeles cohort to study the hypothesis that increased cardiac arrhythmia and decreased HRV are associated with exposure to PM. (2011) reported no "serious arrhythmias" or
Address correspondence to S.M. Bartell, Program in Public Health, 2032 Anteater Instruction \& Research Building, University of California, Irvine, Irvine, CA 92697-3957 USA. Telephone: (949) 824-5919. E-mail: sbartell@uci.edu

Supplemental Material is available online (http:// dx.doi.org/10.1289/ehp.1205914)

We thank the staff of the Department of Epidemiology and of the General Clinical Research Center, University of California, Irvine; Department of Civil and Environmental Engineering, University of Southern California; the California Air Resources Board (CARB); and the South Coast Air Quality Management District. We also thank S. Malik and W. Zhou in the Cardiology Division, University of California, Irvine, for assistance with ambulatory Holter readings.

This project was supported by National Institute of Environmental Health Sciences grant ES-012243, CARB contracts 03-329 and 08-307, and National Center for Research Resources grant MO1 RR00827. J.L. is funded by the Lawrence K. Dodge and Susan Samueli Chairs.

C.S. receives royalties from SKC Inc. for the air sampling device (Sioutas ${ }^{\mathrm{TM}}$ Personal Cascade Impactor Sampler) used in this research. The other authors declare they have no actual or potential competing financial interests.

Received: 20 August 2012; Accepted: 8 July 2013; Advance Publication: 9 July 2013; Final Publication: 1 October 2013. 


\section{Materials and Methods}

Study population. We made repeated ambulatory ECG measurements among 55 elderly nonsmokers with CAD who were recruited from four retirement communities in the Los Angeles Air Basin. Eligibility criteria included age of $\geq 65$ years, history of CAD, being a nonsmoker, and having no exposure to environmental tobacco smoke. CAD diagnoses were obtained by questionnaire or cardiologist interview, and were confirmed with medical records review as described previously (Delfino et al. 2008). Study cardiologists and nurses clinically evaluated 105 potentially eligible participants in our mobile medicine clinic. Twenty-one participants were not eligible to participate in the overall study, 18 dropped out of the ambulatory ECG monitoring portion of the study, and 4 had insufficient ambulatory ECG monitoring time ( $\leq 3$ days). Twelve participants who had pacemakers also were excluded because pacemakers can render arrhythmia and HRV data invalid, leaving 50 participants and 8,952 hr of data. We confirmed the presence and absence of pacemakers using baseline ECG and ambulatory ECG data, and used digital and paper diaries to monitor daily medication use.

This study was approved by the institutional review board of the University of California, Irvine, in 2003. All participants gave informed consent.

Ambulatory ECG monitoring and outcomes. Each participant wore an ambulatory ECG (Holter) monitors for two 5-day periods (Sunday through Friday) during 12 weeks of follow-up: one 5-day period between July and mid-October and one 5-day period between mid-October and February. We used the Burdick model 92513 compact digital Holter recorder and scanner/software system (Burdick Inc., Deerfield, WI), which is a seven-lead, three-channel Holter ECG that has a data acquisition speed of $200 \mathrm{~Hz}$. Each day, the subject removed leads and bathed before a trained research assistant arrived at the subject's home to download ECG data and setup the ECG for a new day. The Holter ECG signals (three channels) were read and analyzed using the Burdick Vision Premier Holter Analysis System, which includes algorithms for QRS labeling, arrhythmia detection, artifact identification, and data correction. A Holter technician from the Noninvasive Laboratory of the University of California, Irvine, Medical Center then screened the data for artifacts and outliers; indications of abnormalities, arrhythmias, ST segment changes and flagged ECG regions were reviewed by physicians.

Arrhythmia outcomes included supraventricular and ventricular arrhythmias in consecutive runs of $\geq 3$ ectopic beats at a rate $\geq 120$ beats per min (bpm) (Berger et al.
2006). The duration of arrhythmias and the number of foci in each hour were recorded. Numbers of arrhythmia events during 24-hr intervals corresponding to the gravimetric particle mass sampling times (afternoon to afternoon) also were recorded. The Holter output for each episode of supraventricular (atrial) tachycardia (SVT) and ventricular tachycardia (VT) was extracted. We defined SVT as paroxysmal supraventricular tachycardia (observed in $n=460$ subject-hours with one or more foci), and VT as single focus ventricular tachycardia ( $n=69$ subjecthours) or multifocal ventricular tachycardia ( $n=232$ subject-hours). Atrial fibrillation ( $n=2$ subject-hours), atrial flutter $(n=2$ subject-hours), atrioventricular block ( $n=12$ subject-hours), and accelerated idioventricular rhythm ( $n=50$ subject-hours) were observed too infrequently to analyze; we calculated subject-hours, including SVT or VT, without regard to these rare events.

We used Burdick Vision Series HRV software to analyze the QRS annotation file described above. All HRV measures were derived from 5-min epochs using acceptable normal-to-normal (N-N) intervals (Task Force of the European Society of Cardiology and the North American Society of Pacing and Electrophysiology 1996). Only beats classified as normal and not preceded by ectopic beats or prolonged R-R intervals were included in the N-N interval estimation. An interpolation algorithm using cubic splines was used to replace missing beats, including the removed ectopic beats and artifacts, premature ventricular contractions (PVCs), and other nonnormal R-R areas (Albrecht and Cohen 1988). N-N intervals < 300 and/or $>3,000 \mathrm{msec}$ or with $\mathrm{N}-\mathrm{N}$ ratios between $<0.8$ or $>1.2$ were rejected. Segments in which $>20 \%$ of $\mathrm{R}-\mathrm{R}$ intervals required replacement were excluded from the analysis.

The HRV outcomes consisted of standard time domain variables (Task Force of the European Society of Cardiology and the North American Society of Pacing and Electrophysiology 1996) measured at the hourly level: standard deviation of normal $\mathrm{R}-\mathrm{R}$ intervals (SDNN), root mean square of the successive differences between R- $\mathrm{R}$ intervals (r-MSSD), and logit percentage of adjacent normal R-R intervals that differed by $>50 \mathrm{msec}$ (logit pNN50). HRV outcomes were computed both for 1- and 24-hr intervals spanning the pollutant sampling periods (described below). However, day/night differences in N-N intervals can contribute to a major fraction of the SDNN magnitude (Kleiger et al 2005). Therefore, for pollutants that were measured hourly, we also conducted analyses that were stratified according to daytime (0600-1900 hours) and nighttime (1900-0600 hours) periods.
The distributions of SDNN, r-MSSD, and pNN50 were moderately right skewed. After removing some extreme outliers, we used three times the median of the absolute deviations of each SDNN or r-MSSD measurement from their median as a cut point for further removal of outliers (Zanobetti et al. 2010). This resulted in a loss of approximately $11 \%$ of hourly SDNN records and $13 \%$ of hourly r-MSSD records. The logit transformation was used for pNN50 with $2.27 \%$ of the hourly pNN50 records excluded because of $\mathrm{pNN} 50=0$.

Environmental exposures. We monitored outdoor air pollutants using a specially equipped trailer parked at each retirement community. Hourly particle exposures for the analysis of both hourly and 24-hr HRV outcomes included total particle number concentrations (condensation particle counter model 3785; TSI Inc., Shoreview, MN), $\mathrm{PM}_{2.5}$ black carbon (BC) (Aethalometer; Magee Scientific, Berkeley, CA), $\mathrm{PM}_{2.5}$ organic and elemental carbon (OC-EC Analyzer model 3F; Sunset Laboratory Inc., Tigard, OR) (Arhami et al. 2006), and $P_{2.5}$ mass using a betaattenuation mass monitor (model 1020; Met One Instruments Inc., Grants Pass, OR). The particle counter detects particle sizes ranging from $5 \mathrm{~nm}$ to $>3,000 \mathrm{~nm}$. We measured hourly pollutant gases including ozone $\left(\mathrm{O}_{3}\right)$ and markers of fossil fuel combustion, namely carbon monoxide (CO) and nitrogen oxides $\left(\mathrm{NO}_{\mathrm{x}}\right)$, using federal reference methods (U.S. Environmental Protection Agency 2013). BC and elemental carbon (EC) are similar, but not identical, measurements of carbon linked to fossil fuel combustion.

We used the Sioutas ${ }^{\mathrm{TM}}$ Personal Cascade Impactor Sampler (SKC Inc., Eighty Four, PA) to measure daily size-fractionated PM mass concentrations (Misra et al. 2002). The analysis included particles $0-0.25 \mu \mathrm{m}$ in diameter $\left(\mathrm{PM}_{0.25}\right)$, accumulation mode particles $0.25-2.5 \mu \mathrm{m}$ in diameter $\left(\mathrm{PM}_{0.25-2.5}\right)$, and coarse mode particles $2.5-10 \mu \mathrm{m}$ in diameter $\left(\mathrm{PM}_{2.5-10}\right) . \mathrm{PM}_{0.25}$ is considered "quasiultrafine" because the traditional cut point for the ultrafine mode is around $0.1-0.2 \mu \mathrm{m}$. Meteorological data were also collected in the air sampling trailer.

We estimated the mass of total organic carbon (OC) attributed to secondary OC (a surrogate of photochemically derived OC) and the mass of OC attributed to primary OC (attributable to primary combustion sources, mostly traffic in the study regions). These estimates were based on the EC tracer method and are described elsewhere (Polidori et al. 2007).

Personal accelerometer data. Given the inverse relationship between physical activity and vagal influences on the heart during high levels of activity (Grossman and Taylor 2007; 
Grossman et al. 2004), it is possible that associations between air pollution and ambulatory HRV could be confounded or modified by different activity levels, especially respiratory sinus arrhythmia as reflected by r-MSSD or pNN50. As such, we electronically monitored physical activity continuously for each 24-hr period with a personal motion logger (Mini-motionlogger; Ambulatory Monitoring Inc., Ardsley, NY), a piezoelectric accelerometer that recorded objective measurements of movement intensity using the unit's high sensitivity proportional integrating measure mode. We discarded accelerometer data at the beginning and end of each daily sampling period to avoid movement artifacts from equipment removal and setup. Valid accelerometer data were available for $92.8 \%$ of all hourly ECG records. We normalized 1-min data by subject-specific $z$-scores, and then determined average movement intensity for hourly periods corresponding to the hourly periods for the HRV and arrhythmia data.

Statistical analysis. Statistical analyses were conducted using SAS software, versions 9.2 and 9.3 (SAS Institute Inc., Cary, NC). Regression models were used to estimate associations between HRV and arrhythmia outcomes with interquartile range (IQR) increases in individual pollutants adjusted for potential confounding variables. Generalized estimating equations (implemented in PROC GENMOD) were used to account for withinsubject correlations induced by the repeated measures design. A Gaussian variance structure was assumed for continuous HRV outcomes (SDNN, r-MSSD, and logit pNN50). For arrhythmia outcomes (VT and SVT), a quasi-Poisson variance was assumed for daily counts, and a quasi-binomial variance was assumed for the absence or presence of VT or SVT events during hourly intervals. Autoregressive correlation was assumed for residual errors from the same individual. For analyses of daily VT counts, we excluded data from one participant who had > $19 \mathrm{VT}$ events/day during the warm season phase because they were highly influential (Cook's D > 0.3). In addition, we excluded VT data from eight other participants who had values $>3$ SD above the mean.

We estimated odds ratios (ORs) for the occurrence of one or more arrhythmia events during hourly intervals in association with pollutant concentrations during the hour before the outcome measurement, and with average pollutant concentrations during the $4 \mathrm{hr}, 8 \mathrm{hr}, 24 \mathrm{hr}, 3$ days, and 5 days before the outcome. We estimated daily rate ratios associated with size-fractionated PM exposures $\left(\mathrm{PM}_{0.25}, \mathrm{PM}_{0.25-2.5}\right.$, and $\left.\mathrm{PM}_{2.5-10}\right)$ averaged during the current 24-hr interval (lag 0) and the previous 24-hr interval (lag 1; 25- to 48-hr average), and averaged over 2 days (during the current and previous $24 \mathrm{hr}$ ). Longer average exposures or lags $>1$ day could not be assessed for PM fractions because PM filters were collected only during the 5 days of Holter monitoring. Both the risk of VT (e.g., Lampert et al. 1994) and air pollutant exposures (Polidori et al. 2007) are well known to differ between daytime and nighttime hours, leading us to investigate modification of pollutant associations with VT by daytime and nighttime hours as an a priori hypothesis. Thus, we fit additional models stratified by this variable and conducted formal hypothesis tests using Cochran's Q statistic (Cochran 1954) to assess the significance of differences in daytime versus nighttime associations.

In secondary analyses, we used interaction terms to test for effect modification by sex, medication use, and self-reported comorbidities. For VT, we also repeated the analyses excluding daytime hours in which participants reported they were away from home.

All effect estimates were adjusted for hourly or daily average actigraph-derived physical activity and heart rate, temperature averaged over the exposure time period, day of week, 5-day study period (July to midOctober or mid-October through February), and retirement community. Exposures were decomposed using the Sheppard et al. (2005) mean-centering approach to implicitly adjust for potential confounding and mismeasurement of exposure by study phase and retirement community (see Supplemental Material, pp. 2-3). We also investigated hour of day as a possible confounder, but it was omitted from final models because of a lack of evidence of any confounding (i.e., there was little change in model coefficients). We assessed statistical significance using a 5\% type I error rate per test, and 95\% confidence intervals (CIs) are reported for point estimates. Because of the relatively large number of tests conducted (multiple pollutants, multiple outcomes, and multiple lag times), the percentage of tests yielding significant associations is reported for major categories of comparisons.

\section{Results}

Nearly half of the study participants had had a previous myocardial infarction; the remainder qualified for enrollment based on coronary artery bypass graft or angioplasty, a positive angiogram or stress test, or clinical diagnosis of CAD (Table 1). In addition, most (68\%) had hypertension, and nearly all (76\%) had hypercholesterolemia. Most participants were male $(62 \%)$ and overweight [mean body mass index (BMI) was 27; 20\% were obese]. Cardiac medications were common, the majority taking $\beta$-adrenergic blocking agents (beta blockers) or hypocholesterolemic agents such as statins. Although the four retirement communities were nonsmoking facilities and none of the participants were current or recent smokers (within 12 months), 44\% were former smokers.

Summary statistics for the outcome variables are shown in Table 2. pNN50 was similar for day and night, but SDNN and r-MSSD were higher for daytime hours than nighttime hours.

Pollutant measurements are described in Table 3. Because two or three participants in the same retirement community were simultaneously monitored on each day, the number of 24-hr pollutant measurements $(n=235)$ is $<500$ measurements, which would have resulted from measuring each participant's personal exposure. Regression effect estimates were standardized to the IQR of each pollutant. The traffic-related air pollutants (primary $\mathrm{OC}, \mathrm{NO}_{\mathrm{x}}, \mathrm{CO}$ ) were highly positively correlated with each other, with pairwise Spearman correlations $\geq 0.75$, whereas

Table 1. Characteristics of participants $(n=50)$.

\begin{tabular}{|c|c|}
\hline Characteristic & $\begin{array}{l}\text { Mean } \pm \text { SD } \\
\text { or } n(\%)\end{array}$ \\
\hline Age (years) & $83.3 \pm 5.95$ \\
\hline $\mathrm{BMI}\left(\mathrm{kg} / \mathrm{m}^{2}\right)$ & $27.0 \pm 3.63$ \\
\hline Obese (BMI > 30) & $10(20)$ \\
\hline \multicolumn{2}{|l|}{ Sex } \\
\hline Male & $31(62)$ \\
\hline Female & $19(38)$ \\
\hline \multicolumn{2}{|l|}{ Cardiovascular history } \\
\hline \multicolumn{2}{|l|}{ Confirmation of CAD ${ }^{a}$} \\
\hline Myocardial infarction & $23(46)$ \\
\hline Coronary artery bypass graft or angioplasty & $16(32)$ \\
\hline Positive angiogram or stress test & $8(16)$ \\
\hline $\begin{array}{l}\text { Clinical diagnosis of coronary } \\
\text { microvascular disease }\end{array}$ & $3(6)$ \\
\hline Current angina pectoris & $14(28)$ \\
\hline Cardiac arrhythmia & $10(20)$ \\
\hline Congestive heart failure & $10(20)$ \\
\hline Hypertension & $34(68)$ \\
\hline Hypercholesterolemia & $38(76)$ \\
\hline \multicolumn{2}{|l|}{ Other medical history } \\
\hline Type 2 diabetes & $7(14)$ \\
\hline COPD or asthma & $5(10)$ \\
\hline Stroke or transient ischemic attack & $8(16)$ \\
\hline \multicolumn{2}{|l|}{ Medications } \\
\hline$\beta$-Adrenergic blocking agents & $30(60)$ \\
\hline Antiarrhythmic drugs & $4(8)$ \\
\hline Digoxin & $3(6)$ \\
\hline ACE inhibitors & $20(40)$ \\
\hline HMG-CoA reductase inhibitors (statins) & $27(54)$ \\
\hline Platelet aggregation inhibitors or Coumadin & $17(34)$ \\
\hline Calcium channel blockers & $17(34)$ \\
\hline $\begin{array}{l}\text { At least one beta-blocker or calcium } \\
\text { channel blocker medication }{ }^{b}\end{array}$ & $37(74)$ \\
\hline \multicolumn{2}{|l|}{ Smoking history } \\
\hline Never-smoker & $28(56)$ \\
\hline Former smoker ${ }^{c}$ & $22(44)$ \\
\hline
\end{tabular}

Abbreviations: $A C E$, angiotensin I-converting enzyme; COPD, chronic obstructive pulmonary disease; $\mathrm{HMG}-\mathrm{CoA}$, 3-hydroxy-3-methylglutaryl coenzyme A.

${ }^{a}$ Each category is hierarchical (excludes being in above diagnostic category). ${ }^{b} \mathrm{~A}$ beta-blocker, a calcium channel blocker, or an antiarrhythmic drug having beta-blocker and/or calcium channel antagonistic effects. ${ }^{c}$ No smoking within 12 months. 
$\mathrm{O}_{3}$ was negatively correlated and secondary OC was not correlated with these primary combustion-related pollutants (Supplemental Material, Table S1). Given the strong correlation among primary pollutants, our regression models test one pollutant at a time.

Associations between daily count of VT events and outdoor air pollutants, adjusted for confounding variables, are shown in Table 4. An IQR increase in 24-hr average $\mathrm{PM}_{2.5}$ was associated with a $50 \%$ increase in the daily rate of VT events (95\% CI: 2, 20\%). The estimated effect of 3-day average $\mathrm{PM}_{2.5}$ on daily VT was nearly identical, although not statistically significant. Analysis of $\mathrm{PM}_{2.5}$ constituents indicated statistically significant associations between daily VT and average exposures during the previous 24-hr for BC, EC, total OC, and primary OC. Average total OC during the previous 24-hr was strongly associated with daily VT [relative risk $(\mathrm{RR})=3.06 ; 95 \% \mathrm{CI}$ :

Table 2. Distribution of outcome variables.

\begin{tabular}{|c|c|c|c|c|}
\hline Outcome & Mean \pm SD & Median & Minimum & Maximum \\
\hline \multicolumn{5}{|l|}{$\mathrm{VT}^{a}$} \\
\hline No. during $24 \mathrm{hr}$ & $1.73 \pm 11.14$ & 0 & 0 & 158 \\
\hline \multicolumn{5}{|l|}{$\mathrm{SVT}^{b}$} \\
\hline No. during $24 \mathrm{hr}$ & $1.32 \pm 3.46$ & 0 & 0 & 36 \\
\hline \multicolumn{5}{|l|}{ SDNN } \\
\hline Day and night ${ }^{c}$ & $72.91 \pm 34.98$ & 66 & 3 & 159 \\
\hline Daytime & $74.26 \pm 34.19$ & 68 & 6 & 159 \\
\hline Nighttime & $69.92 \pm 36.50$ & 62 & 3 & 159 \\
\hline \multicolumn{5}{|l|}{$r-M S S D$} \\
\hline Day and night & $49.25 \pm 45.67$ & 29 & 0.06 & 183 \\
\hline Daytime & $50.32 \pm 46.71$ & 29 & 0.06 & 183 \\
\hline Nighttime & $46.88 \pm 43.18$ & 29 & 0.11 & 183 \\
\hline \multicolumn{5}{|l|}{ pNN50 } \\
\hline Day and night & $22.4 \pm 28.7$ & 5.76 & 0 & 97.3 \\
\hline Daytime & $22.5 \pm 28.4$ & 5.85 & 0 & 91.5 \\
\hline Nighttime & $22.4 \pm 28.9$ & 5.65 & 0 & 97.3 \\
\hline
\end{tabular}

${ }^{a}$ Based on VT events observed in 301 hourly periods among 18 participants. ${ }^{b}$ Based on SVT events observed in 460 hourly periods among 39 participants; 13 of those participants also experienced VT events. 'Daytime is 0600-1900 hours; nighttime is $1900-0600$ hours.

Table 3. Distribution of outdoor air pollution variables.

\begin{tabular}{lcccccr}
\hline Exposure $(24-h r \text { averages })^{a}$ & $n$ & $n$ missing $^{a}$ & Mean \pm SD & IQR & Minimum & Maximum \\
\hline Continuously measured PM & & & & & & \\
$\mathrm{PM}_{2.5}\left(\mu \mathrm{gg} / \mathrm{m}^{3}\right)^{b}$ & 235 & 0 & $21.1 \pm 11.4$ & 16.1 & 2.3 & 77.4 \\
Particle number $\left(\mathrm{no} . / \mathrm{cm}^{3}\right)$ & 184 & 51 & $12,818 \pm 5,889$ & 6,351 & 2,019 & 30,180 \\
$\mathrm{BC}\left(\mu \mathrm{g} / \mathrm{m}^{3}\right)$ & 235 & 0 & $1.7 \pm 0.8$ & 1.0 & 0.3 & 4.5 \\
EC $\left(\mu \mathrm{g} / \mathrm{m}^{3}\right)$ & 198 & 37 & $1.52 \pm 0.6$ & 0.9 & 0.3 & 3.3 \\
OC $\left(\mu \mathrm{g} / \mathrm{m}^{3}\right)$ & 188 & 47 & $7.8 \pm 3.7$ & 5.2 & 2.5 & 18.7 \\
Primary OC $\left(\mu \mathrm{g} / \mathrm{m}^{3}\right)$ & 157 & 78 & $5.3 \pm 2.9$ & 4.4 & 41.4 & 12.6 \\
Secondary OC $\left(\mu \mathrm{g} / \mathrm{m}^{3}\right)$ & 157 & 78 & $2.9 \pm 1.5$ & 2.1 & 0.3 & 7.7 \\
Size-fractionated PM $\left(\mu \mathrm{g} / \mathrm{m}^{3}\right)^{b}$ & & & & & & \\
$\mathrm{PM}_{0.25}$ & 217 & 18 & $9.8 \pm 4.1$ & 7.0 & 2.5 & 30.1 \\
$\mathrm{PM}_{0.25-2.5}$ & 226 & 9 & $11.4 \pm 9.4$ & 10.6 & 1.0 & 66.8 \\
$\mathrm{PM}_{2.5-10}$ & 217 & 18 & $9.4 \pm 5.0$ & 5.5 & 0.3 & 24.6 \\
$\mathrm{Criteria} \mathrm{pollutant} \mathrm{gases}_{\mathrm{NO}}(\mathrm{ppb})$ & & & & & & \\
$\mathrm{CO}(\mathrm{ppm})$ & 235 & 0 & $46.6 \pm 31.4$ & 42.3 & 3.2 & 183.7 \\
$\mathrm{O}_{3}(\mathrm{ppb})$ & 224 & 11 & $0.53 \pm 0.30$ & 0.42 & 0.01 & 1.68 \\
\hline
\end{tabular}

aThe continuously measured PM variables were averaged hourly and are presented as 24-hr averages; there were fewer missing observations for $\mathrm{BC}, \mathrm{PM}_{2.5}$, and the gases because two samplers were operated in parallel at all times; there was more missing primary and secondary $\mathrm{OC}$ than total $\mathrm{OC}$ because of missing predictor data used to estimate these two $\mathrm{OC}$ fractions, including $\mathrm{EC}$. ${ }^{b} \mathrm{PM}_{2.5}$ mass was measured hourly with a pair of beta-attenuation mass monitors, whereas the size-fractionated PM mass was measured daily with a personal cascade impactor sampler, which was missing more data.

$1.82,5.17$ per IQR increase], with the strongest constituent-specific association being with with secondary OC. Ozone also was strongly associated with daily VT, particularly the 3-day $(\mathrm{RR}=2.95 ; 95 \% \mathrm{CI}: 1.29,6.74)$ daily VT varied by averaging time, ranging from a $0 \%$ to $31 \%$ increase for $\mathrm{PM}_{0.25}$ and increase to $20 \%$ outlying subject with > 19 events/day, RRs for VT events were mostly larger than reported ere, often $>5$ with wide CIs (data not shown). time and nighttime models using occurrence of one or more VT events per hour as the outcome variable. In these models daytime increases in $\mathrm{PM}_{2.5}$ concentrations for all averaging times, but none of the associations 
$1.02,1.39)$ and 8 -hr ozone $(\mathrm{RR}=1.25$; $95 \%$ CI: $1.00,1.56$ ).

Few significant associations were estimated for PM variables and the three hourly HRV outcomes (SDNN, r-MSSD, and logit pNN50): None of 126 tests were significant at the $1 \%$ level, and only 6 tests $(4.8 \%)$ were significant at the 5\% level (see Supplemental Material, Table S3). In contrast, the 54 tests for outdoor gaseous pollutants $\left(\mathrm{O}_{3}, \mathrm{NO}_{\mathrm{x}}\right.$, and $\mathrm{CO})$ with hourly HRV yielded 3 significant associations $(5.6 \%)$ at the $1 \%$ level, and 9 significant associations (16.7\%) at the 5\% level, primarily showing unexpected increases in HRV associated with IQR increases in $\mathrm{NO}_{\mathrm{x}}$ and $\mathrm{CO}$ exposure at 4- to 8-hr lags. Similarly, daily lag 0, 1, and 2-day average size-fractionated PM mass concentrations also were not significantly associated with 24-hr SDNN (data not shown).

We tested potential effect measure modification of air pollutant effects on 4-hr, 8-hr, and 1-day SDNN by medication use and found no significant differences except for ACE inhibitors (Figure 1). Eight-hour $\mathrm{PM}_{2.5}$, 8-hr BC, 4-hr secondary OC, and 4-hr and 8-hr ozone were significantly and inversely associated with hourly SDNN only among the 20 participants taking ACE inhibitors; in contrast, 4-hr and 8-hr EC, 8-hr BC, and 8 -hr OC were significantly and positively associated with hourly SDNN among the participants not taking ACE inhibitors ( $p$-values not shown).

\section{Discussion}

Prior to 2005, few studies of HRV and air pollution monitored participants using ambulatory ECG. Instead, most studies recorded short ECG strips at rest during in-clinic visits to control for effects of physical activity on respiratory sinus arrhythmia (Delfino et al. 2005). Here, we opted for activity-adjusted ambulatory ECG collected during two 5-day intervals for each participant along with detailed home air pollutant monitoring, which allowed estimation of PM and PM constituent effects on both HRV and cardiac arrhythmias.

Table 4. Associations ${ }^{a}$ of ventricular tachycardia with outdoor air pollutants, per IQR.

\begin{tabular}{|c|c|c|c|c|c|c|c|c|c|}
\hline $\begin{array}{l}\text { Exposure and } \\
\text { averaging time }\end{array}$ & $\begin{array}{c}\text { Daily } \\
\text { RR (95\% CI) }\end{array}$ & $\begin{array}{c}\text { Hourly } \\
\text { daytime }^{b} \\
\text { OR }(95 \% \mathrm{Cl})\end{array}$ & $\begin{array}{c}\text { Hourly } \\
\text { nighttime }^{b} \\
\text { OR }(95 \% \text { Cl) }\end{array}$ & $p$-Value ${ }^{c}$ & $\begin{array}{l}\text { Exposure and } \\
\text { averaging time }\end{array}$ & $\begin{array}{c}\text { Daily } \\
\text { RR }(95 \% \text { CI) }\end{array}$ & $\begin{array}{c}\text { Hourly } \\
\text { daytime }^{b} \\
\text { OR }(95 \% \text { CI) }\end{array}$ & $\begin{array}{c}\text { Hourly } \\
\text { nighttime }^{b} \\
\text { OR }(95 \% \text { Cl) }\end{array}$ & $p$-Value ${ }^{c}$ \\
\hline $\mathrm{PM}_{2.5}$ & & & & & Secondary OC & & & & \\
\hline $1 \mathrm{hr}$ & - & $1.06(0.83,1.35)$ & $0.94(0.60,1.47)$ & 0.645 & $1 \mathrm{hr}$ & - & $1.18(0.90,1.54)$ & $1.12(0.76,1.66)$ & 0.833 \\
\hline $4 \mathrm{hr}$ & - & $1.21(0.95,1.54)$ & $0.94(0.56,1.58)$ & 0.391 & $4 \mathrm{hr}$ & - & $1.68(1.21,2.33)^{\#}$ & $1.24(0.76,2.02)$ & 0.307 \\
\hline $8 \mathrm{hr}$ & - & $1.17(0.95,1.44)$ & $0.86(0.51,1.45)$ & 0.284 & $8 \mathrm{hr}$ & - & $1.86(1.06,3.26)^{* *}$ & $1.31(0.90,1.90)$ & 0.301 \\
\hline $24 \mathrm{hr}$ & $1.50(1.02,2.20)^{* *}$ & $1.23(0.99,1.52)^{*}$ & $0.85(0.64,1.12)$ & $0.039 * *$ & $24 \mathrm{hr}$ & $1.43(0.93,2.18)^{*}$ & $1.18(0.69,2.02)$ & $1.45(0.70,3.00)$ & 0.653 \\
\hline 3 day & $1.51(0.85,2.70)$ & $1.26(0.99,1.61)^{*}$ & $1.19(0.84,1.67)$ & 0.778 & 3 day & $1.28(0.47,3.47)$ & $0.68(0.20,2.30)$ & $2.30(0.41,13.0)$ & 0.261 \\
\hline $\begin{array}{l}5 \text { day } \\
\text { Particle number }\end{array}$ & $1.16(0.59,2.29)$ & $1.30(0.78,2.17)$ & $2.15(0.90,5.11)^{*}$ & 0.328 & 5 day & $2.27(0.79,6.58)$ & $0.97(0.22,4.15)$ & $1.68(0.54,5.23)$ & 0.558 \\
\hline $1 \mathrm{hr}$ & - & $1.06(0.86,1.30)$ & $0.77(0.59,1.01)^{*}$ & $0.071^{*}$ & $\mathrm{PM}_{0.25}$ & & & & \\
\hline $4 \mathrm{hr}$ & - & $1.05(0.84,1.31)$ & $0.90(0.62,1.30)$ & 0.491 & Lag 0 (24 hr) & $1.04(0.67,1.60)$ & - & - & \\
\hline $8 \mathrm{hr}$ & - & $0.90(0.64,1.26)$ & $1.09(0.70,1.70)$ & 0.506 & Lag 1 (25-48 hr) & $1.20(0.97,1.47)^{*}$ & - & - & \\
\hline $24 \mathrm{hr}$ & $0.70(0.41,1.20)$ & $0.90(0.55,1.46)$ & $0.64(0.31,1.31)$ & 0.442 & 2 day & $1.29(0.73,2.29)$ & - & - & \\
\hline 3 day & $0.42(0.09,1.94)$ & $1.16(0.41,3.26)$ & $0.70(0.26,1.92)$ & 0.497 & $\mathrm{PM}_{0.25-2.5}$ & & & & \\
\hline 5 day & $0.20(0.02,1.67)$ & $2.43(0.55,10.7)$ & $0.88(0.10,7.89)$ & 0.453 & Lag 0 (24 hr) & $1.31(1.05,1.64)^{* *}$ & - & - & \\
\hline $\mathrm{BC}$ & & & & & Lag 1 (25-48 hr) & $1.00(0.78,1.28)$ & - & - & \\
\hline $\begin{array}{l}1 \mathrm{hr} \\
4 \mathrm{hr}\end{array}$ & - & $\begin{array}{l}1.07(0.94,1.22) \\
1.07(0.91,1.25)\end{array}$ & $\begin{array}{l}0.84(0.53,1.34) \\
0.75(0.44,1.29)\end{array}$ & $\begin{array}{l}0.327 \\
0.215\end{array}$ & 2 day & $1.30(0.96,1.77)^{*}$ & - & - & \\
\hline $8 \mathrm{hr}$ & - & $1.23(1.06,1.44)^{\#}$ & $0.69(0.46,1.03)^{*}$ & $0.008^{\#}$ & $\mathrm{PM}_{2.5-10}$ & & & & \\
\hline $24 \mathrm{hr}$ & $1.40(1.06,1.84)^{* *}$ & $1.30(0.98,1.72)^{*}$ & $0.74(0.54,1.00)^{*}$ & $0.008^{\#}$ & Lag 0 (24 hr) & $1.20(0.90,1.59)$ & - & - & \\
\hline 3 day & $1.59(0.77,3.30)$ & $1.88(1.30,2.73)^{\#}$ & $1.38(0.78,2.42)$ & 0.365 & Lag 1 (25-48 hr) & $0.87(0.71,1.06)$ & - & - & \\
\hline 5 day & $1.36(0.64,2.91)$ & $2.68(1.32,5.42)^{\#}$ & $2.63(0.87,8.00)^{*}$ & 0.978 & 2 day & $0.97(0.66,1.44)$ & - & - & \\
\hline $\mathrm{EC}$ & & & & & $\mathrm{O}_{3}$ & & & & \\
\hline $1 \mathrm{hr}$ & - & & $0.79(0.56,1.11)$ & & $1 \mathrm{hr}$ & - & $1.33(1.09,1.62)^{\#}$ & $0.98(0.66,1.47)$ & 0.184 \\
\hline $\begin{array}{l}4 \mathrm{hr} \\
8 \mathrm{hr}\end{array}$ & - & $\begin{array}{l}0.96(0.85,1.08) \\
1.09(0.92,1.30)\end{array}$ & $\begin{array}{l}0.80(0.47,1.35) \\
0.63(0.38,1.06)^{*}\end{array}$ & $\begin{array}{l}0.507 \\
0.049 * *\end{array}$ & $4 \mathrm{hr}$ & - & $1.37(1.06,1.77)^{* *}$ & $0.99(0.64,1.53)$ & 0.213 \\
\hline $24 \mathrm{hr}$ & $1.55(1.09,2.21)^{* *}$ & $1.24(0.95,1.60)$ & $0.69(0.50,0.96)^{* *}$ & $0.006^{\#}$ & $8 \mathrm{hr}$ & - & $1.37(0.98,1.91)^{*}$ & $1.13(0.74,1.70)$ & 0.472 \\
\hline 3 day & $1.46(0.65,3.30)$ & $2.10(1.08,4.09)^{* *}$ & $1.09(0.54,2.22)$ & 0.187 & $24 \mathrm{hr}$ & $1.60(1.12,2.30)^{* *}$ & $0.66(0.35,1.25)$ & $2.68(1.32,5.46)^{\#}$ & $0.004^{\#}$ \\
\hline 5 day & $1.90(0.82,4.37)$ & $3.07(0.90,10.5)^{*}$ & $1.57(0.69,3.58)$ & 0.375 & 3 day & $2.95(1.29,6.74)^{* *}$ & $0.30(0.08,1.14)^{*}$ & $1.43(0.45,4.57)$ & $0.082^{*}$ \\
\hline $\mathrm{OC}$ & & & & & 5 day & $0.93(0.10,8.16)$ & $0.05(0.01,0.53)^{* *}$ & $2.05(0.42,9.86)$ & $0.010^{* *}$ \\
\hline $1 \mathrm{hr}$ & - & $1.24(0.78,1.97)$ & $0.91(0.49,1.68)$ & 0.431 & $\mathrm{NO}_{\mathrm{x}}$ & & & & \\
\hline $4 \mathrm{hr}$ & - & $2.13(1.31,3.49)^{\#}$ & $0.84(0.38,1.86)$ & $0.051^{*}$ & $1 \hat{h r}$ & - & $0.98(0.75,1.29)$ & $1.13(0.72,1.78)$ & 0.585 \\
\hline $8 \mathrm{hr}$ & - & $2.58(1.47,4.52)^{\#}$ & $0.65(0.23,1.81)$ & $0.021^{* *}$ & $4 \mathrm{hr}$ & - & $0.99(0.77,1.27)$ & $0.92(0.55,1.54)$ & 0.800 \\
\hline $\begin{array}{l}24 \mathrm{hr} \\
3 \text { day }\end{array}$ & $\begin{array}{l}3.06(1.82,5.17)^{\#} \\
2.13(0.60,7.51)\end{array}$ & $\begin{array}{l}1.81(1.08,3.06)^{* *} \\
2.76(0.40,19.02)\end{array}$ & $\begin{array}{l}0.57(0.19,1.69) \\
1.73(0.65,4.65)\end{array}$ & $\begin{array}{l}0.060^{*} \\
0.673\end{array}$ & $8 \mathrm{hr}$ & - & $1.15(0.90,1.47)$ & $0.67(0.35,1.27)$ & 0.120 \\
\hline 5 day & $5.95(0.79,44.8)^{*}$ & $4.22(0.25,71.7)$ & $3.13(0.25,38.6)$ & 0.877 & $24 \mathrm{hr}$ & $1.37(0.99,1.88)^{*}$ & $1.49(0.85,2.62)$ & $0.54(0.28,1.03)^{*}$ & $0.021 * *$ \\
\hline Primary OC & & & & & 3 day & $1.80(0.45,7.12)$ & $2.90(0.87,9.68)^{*}$ & $1.00(0.30,3.30)$ & 0.219 \\
\hline $1 \mathrm{hr}$ & - & $0.85(0.65,1.13)$ & $0.89(0.54,1.46)$ & 0.888 & 5 day & $1.70(0.54,5.40)$ & $7.98(1.48,43.0)^{* *}$ & $1.34(0.14,13.1)$ & 0.217 \\
\hline $4 \mathrm{hr}$ & - & $0.93(0.62,1.39)$ & $0.91(0.44,1.88)$ & 0.966 & $\mathrm{CO}$ & & & & \\
\hline $8 \mathrm{hr}$ & - & $1.07(0.54,2.09)$ & $0.64(0.30,1.37)$ & 0.326 & $1 \mathrm{hr}$ & - & $1.03(0.82,1.30)$ & $0.96(0.66,1.40)$ & 0.730 \\
\hline $24 \mathrm{hr}$ & $2.64(1.13,6.21)^{* *}$ & $1.90(0.64,5.61)$ & $0.99(0.34,2.86)$ & 0.400 & $4 \mathrm{hr}$ & - & $1.06(0.84,1.34)$ & $0.79(0.55,1.15)$ & 0.192 \\
\hline 3 day & $2.16(0.69,6.77)$ & $2.07(0.57,7.55)$ & $0.78(0.31,1.98)$ & 0.231 & $8 \mathrm{hr}$ & - & $1.11(0.88,1.39)$ & $0.68(0.47,0.98)^{* *}$ & $0.025^{* *}$ \\
\hline \multirow[t]{3}{*}{5 day } & $3.15(0.30,33.3)$ & $11.2(0.49,258)$ & $0.62(0.07,5.51)$ & 0.137 & $24 \mathrm{hr}$ & $1.18(0.84,1.65)$ & $0.84(0.45,1.56)$ & $0.53(0.32,0.89)^{* *}$ & 0.276 \\
\hline & & & & & 3 day & $2.20(0.82,5.94)$ & $1.03(0.20,5.35)$ & $1.04(0.30,3.63)$ & 0.994 \\
\hline & & & & & 5 day & $0.84(0.23,3.03)$ & $1.12(0.14,8.66)$ & $1.06(0.10,11.0)$ & 0.973 \\
\hline
\end{tabular}

${ }^{a}$ All models were adjusted for daily average actigraph-derived physical activity and heart rate, temperature of the same lag average, day of week, seasonal study phase (mean cen-

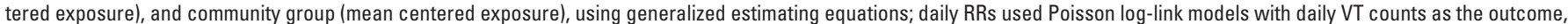

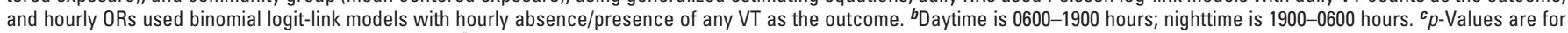
heterogeneity of $\mathrm{OR}$ by day/night. ${ }^{*} p<0.1 .{ }^{* *} p<0.05 .{ }^{\#} p<0.01$. 
Apart from the participants taking ACE inhibitors, these data do not show convincing associations between outdoor pollutants and HRV or SVT after adjusting for likely confounding variables. We believe that our community-based exposure measurements are more accurate and our confounding controls are as good or better than those used in previous investigations, which often relied on ambient pollutant monitoring at central sites and lacked actigraph physical activity data. We recognize, however, that outdoor air pollutant concentrations measured at home are only a surrogate for personal exposure because they do not capture air pollutant exposures during time spent away from the home or indoor pollutant sources. VT associations with pollutants were similar when diary-reported hours away from home were excluded, suggesting that time spent away from home is not a confounder in this setting.

Barclay et al. (2009) suggested that the cations, such as digitalis, which is vagotonic, may mitigate adverse effects of PM on HRV. Consistent with this possibility, de Hartog et al. (2009) observed associations between PM and reduced SDNN only in CAD patients not taking beta-blockers. However, we did not find any evidence that beta-blockers or other between air pollutants and HRV, with the exception of ACE inhibitors.

We observed evidence of negative associations between air pollutants and SDNN among participants using ACE inhibitors, in contrast with null or positive associations with the same pollutants among non-users. A similar finding was reported in a recent ambulatory ECG study of 1,607 participants 50-72 years of age, in which 10-year average $\mathrm{PM}_{10}$ was associated with decreased HRV only among the 97 participants taking ACE inhibitors (Adam et al. 2012). These findings use of beta-blockers and other cardiac medicardiac medications modified associations

may be related to the well-known side effect of ACE inhibitor-induced cough. Several mechanisms for this side effect have been proposed, including the accumulation in the airways of the protussive mediators bradykinin and substance $\mathrm{P}$, which are degraded by ACE, and/or activation of bradykinin receptors on pulmonary rapidly adapting vagal afferents by ACE inhibitors (Dicpinigaitis 2006; Hargreaves et al. 1992). Thus the apparent reduction in SDNN in response to air pollutant exposures among participants using ACE inhibitors might be explained by the stimulation of pulmonary vagal afferents by bradykinin, resulting in increased parasympathetic tone and decreased HRV.

We estimated strong associations between PM and VT in our participants. One study of patients with implanted cardiac defibrillators (ICDs) reported no association of VT with ambient air pollution (Metzger et al. 2007), whereas two other studies did (Dockery et al. 2005; Ljungman et al. 2008). Our participants (mean age: 83 years) were older than those in previous studies, and only one had an ICD (this subject had no VT events). Similarly, Folino et al. (2009) reported strong associations between PM and VT, but not HRV, in CAD patients in their Holter study. Another Holter study of CAD patients reported associations between PM exposures and VT, but did not report any findings on HRV (Berger et al. 2006). We previously reported that other clinically important outcomes were associated with PM in our study participants, including blood pressure, ischemic ST segment depression, and markers of systemic inflammation and platelet activation that might contribute to PM-related cardiac electrical effects (Delfino et al. 2009, 2010a, 2010b, 2011).

Evidence of day and night effect modification of associations between VT and many pollutants might result from differences in

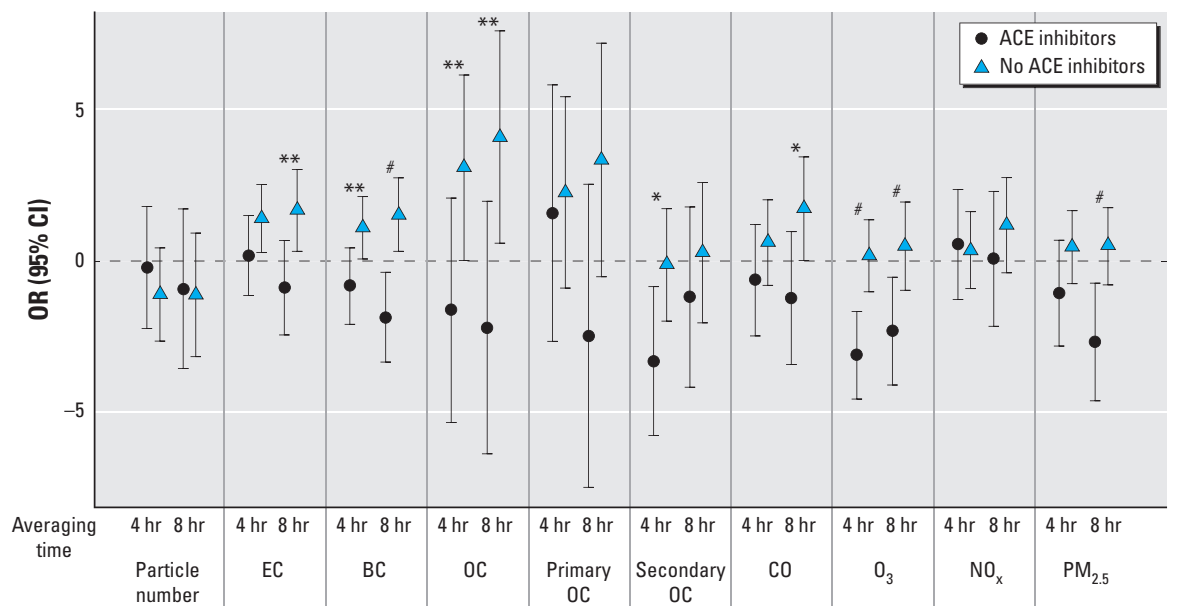

Figure 1. Associations of SDNN with outdoor air pollutants: effect modification by ACE inhibitor use. ${ }^{*} p<0.1,{ }^{* *} p<0.05,{ }^{\#} p<0.01$, compared with no effect modification by ACE inhibitor use. indoor infiltration conditions and air pollutant composition between daytime and nighttime. For example, personal exposure to $\mathrm{O}_{3}$ might differ substantially between the day and night because of the use of air conditioning and reduced time outdoors during hotter daytime hours and greater exposure to outdoor air during cooler nighttime hours. This might explain the unexpected inverse association between VT and outdoor $\mathrm{O}_{3}$ during the daytime. It might also reflect differences in cardiac response to air pollutants between waking and sleeping hours, although we do not know of any specific mechanism to explain this.

\section{Conclusions}

Our findings support the hypothesis that particulate air pollutant exposure increases the risk of VT (consecutive runs of $\geq 3$ ectopic beats at a rate $\geq 120 \mathrm{bpm}$ ) in a population of elderly persons with CAD. An increased rate of arrhythmia at higher PM concentrations has direct medical relevance and strong support in the present study. However, decreased HRV was not associated with air pollutants except in the subset of participants taking ACE inhibitors $(n=20)$. Future panel studies on cardiac effects of PM exposure might benefit from assessment of other mechanisms in addition to HRV.

\section{REFERENCES}

Adam M, Felber Dietrich D, Schaffner E, Carballo D, Barthélémy JC, Gaspoz JM, et al. 2012. Long-term exposure to traffic-related $\mathrm{PM}_{10}$ and decreased heart rate variability: is the association restricted to subjects taking ACE inhibitors? Environ Int 48:9-16.

Albrecht P, Cohen RJ. 1988. Estimation of heart rate power spectrum bands from real-world data: dealing with ectopic beats and noisy data. Comput Cardiol 15:311-314.

Arhami M, Kuhn T, Fine PM, Delfino RJ, Sioutas C. 2006. Effects of sampling artifacts and operating parameters on the performance of a semi-continuous particulate $\mathrm{EC} / \mathrm{OC}$ monitor. Environ Sci Technol 40:945-953.

Ayres JG, Borm P, Cassee FR, Castranova V, Donaldson K, Ghio A, et al. 2008. Evaluating the toxicity of airborne particulate matter and nanoparticles by measuring oxidative stress potential-a workshop report and consensus statement. Inhal Toxicol 20:75-99.

Barclay JL, Miller BG, Dick S, Dennekamp M, Ford I, Hillis GS et al. 2009. A panel study of air pollution in subjects with heart failure: negative results in treated patients. 0ccup Environ Med 66:325-334.

Berger A, Zareba W, Schneider A, Rückerl R, Ibald-Mulli A, Cyrys J, et al. 2006. Runs of ventricular and supraventricular tachycardia triggered by air pollution in patients with coronary heart disease. J Occup Environ Med 48:1149-1158.

Brook RD, Rajagopalan S, Pope CA III, Brook JR, Bhatnagar A, Diez-Roux AV, et al. 2010. Particulate matter air pollution and cardiovascular disease: an update to the scientific statement from the American Heart Association. Circulation 121:2331-2378.

Cochran WG. 1954. The combination of estimates from different experiments. Biometrics 10:101-129.

de Hartog JJ, Lanki T, Timonen KL, Hoek G, Janssen NA Ibald-Mulli $A$, et al. 2009. Associations between $\mathrm{PM}_{2.5}$ and heart rate variability are modified by particle composition and beta-blocker use in patients with coronary heart disease. Environ Health Perspect 117:105-111; doi:10.1289/ ehp.11062.

Delfino RJ, Gillen DL, Tjoa T, Staimer N, Polidori A, Arhami M, et al. 2011. Electrocardiographic ST-segment depression 
and exposure to traffic-related aerosols in elderly subjects with coronary artery disease. Environ Health Perspect 119:196-202; doi:10.1289/ehp.1002372.

Delfino RJ, Sioutas C, Malik S. 2005. Potential role of ultrafine particles in associations between airborne particle mass and cardiovascular health. Environ Health Perspect 113:934-946; doi:10.1289/ehp.7938.

Delfino RJ, Staimer N, Tjoa T, Arhami M, Polidori A, George SC, et al. 2010a. Associations of primary and secondary organic aerosols with airway and systemic inflammation in an elderly panel cohort. Epidemiology 21:892-902.

Delfino RJ, Staimer N, Tjoa T, Gillen D, Polidori A, Arhami M, et al. 2009. Air pollution exposures and circulating biomarkers of effect in a susceptible population: clues to potential causal component mixtures and mechanisms. Environ Health Perspect 117:1232-1238; doi:10.1289/ ehp.0800194.

Delfino RJ, Staimer N, Tjoa T, Polidori A, Arhami M, Gillen DL, et al. 2008. Circulating biomarkers of inflammation, antioxidant activity, and platelet activation are associated with primary combustion aerosols in subjects with coronary artery disease. Environ Health Perspect 116:898-906; doi:10.1289/ehp.11189.

Delfino RJ, Tjoa T, Gillen D, Staimer N, Polidori A, Arhami M, et al. 2010b. Traffic-related air pollution and blood pressure in elderly subjects with coronary artery disease. Epidemiology 21:396-404.

Dicpinigaitis PV. 2006. Potential future therapies for the management of cough: ACCP evidence-based clinical practice guidelines. Chest 129(supp 1):284S-286S.

Dockery DW, Luttmann-Gibson H, Rich DO, Link MS, Mittleman MA, Gold DR, et al. 2005. Association of air pollution with increased incidence of ventricular tachyarrhythmias recorded by implanted cardioverter defibrillators. Environ Health Perspect 113:670-674; doi:10.1289/ehp.7767.

Folino AF, Scapellato ML, Canova C, Maestrelli P, Bertorelli G, Simonato $L$, et al. 2009. Individual exposure to particulate matter and the short-term arrhythmic and autonomic profiles in patients with myocardial infarction. Eur Heart J 30:1614-1620.
Griendling KK, FitzGerald GA. 2003. Oxidative stress and cardiovascular injury. Part II: Animal and human studies. Circulation 108:2034-2040.

Grossman P, Taylor EW. 2007. Toward understanding respiratory sinus arrhythmia: relations to cardiac vagal tone, evolution and biobehavioral functions. Biol Psychol 74:263-285

Grossman P, Wilhelm FH, Spoerle M. 2004. Respiratory sinus arrhythmia, cardiac vagal control, and daily activity. Am Physiol Heart Circ Physiol 287:H728-H734.

Hampel R, Schneider A, Bruske I, Zareba W, Cyrys Rückerl $\mathrm{R}$, et al. 2010. Altered cardiac repolarization in association with air pollution and air temperature among myocardial infarction survivors. Environ Health Perspect 118:1755-1761; doi:10.1289/ehp.1001995.

Hargreaves M, Ravi K, Senaratne MP, Kappagoda CT. 1992. Responses of airway rapidly adapting receptors to bradykinin before and after administration of enalapril in rabbits. Clin Sci (Lond) 83:399-407.

He F, Shaffer ML, Rodriguez-Colon S, Yanosky JD, Bixler E, Cascio WE, et al. 2011. Acute effects of fine particulate air pollution on cardiac arrhythmia: the APACR Study. Environ Health Perspect 119:927-932; doi:10.1289/ehp.1002640.

Kleiger RE, Stein PK, Bigger JT Jr. 2005. Heart rate variability: measurement and clinical utility. Ann Noninvasive Electrocardiol 10:88-101.

Lampert R, Rosenfeld L, Batsford W, Lee F, McPherson C. 1994 Circadian variation of sustained ventricular tachycardia in patients with coronary artery disease and implantable cardioverter-defibrillators. Circulation 90:241-247.

Link MS, Dockery DW. 2010. Air pollution and the triggering of cardiac arrhythmias. Curr Opin Cardiol 25:16-22.

Ljungman PLS, Berglind N, Holmgren C, Gadler F, Edvardsson N Pershagen $\mathrm{G}$, et al. 2008. Rapid effects of air pollution on ventricular arrhythmias. Eur Heart J 29:2894-2901.

Metzger KB, Klein M, Flanders WD, Peel JL, Mulholland JA Langberg JJ, et al. 2007. Ambient air pollution and cardiac arrhythmias in patients with implantable defibrillators. Epidemiology 18:585-592.

Mills NL, Finlayson AE, Gonzalez MC, Törnqvist H, Barath S, Vink $E$, et al. 2011. Diesel exhaust inhalation does not affect heart rhythm or heart rate variability. Heart 97:544-550.
Misra C, Singh M, Hall P, Sioutas C. 2002. Development and evaluation of a personal cascade impactor sampler (PCIS). J Aerosol Science 33:1027-1047.

Polidori A, Arhami M, Delfino RJ, Allen R, Sioutas C. 2007. Indoor-outdoor relationships, trends and carbonaceous content of fine particulate matter in retirement communities of the Los Angeles basin. J Air Waste Manage Assoc 57:366-379.

Schneider A, Hampel R, Ibald-Mulli A, Zareba W, Schmidt G, Schneider R, et al. 2010. Changes in deceleration capacity of heart rate and heart rate variability induced by ambient air pollution in individuals with coronary artery disease. Part Fibre Toxicol 7:29; doi:10.1186/1743-8977-7-29.

Sheppard L, Slaughter JC, Schildcrout J, Liub LJS, Lumley T. 2005. Exposure and measurement contributions to estimates of acute air pollution effects. J Expos Anal Environ Epidemiol 15:366-376.

Task Force of the European Society of Cardiology and the North American Society of Pacing and Electrophysiology. 1996. Heart rate variability: standards of measurement, physiological interpretation, and clinical use. Circulation 93:1043-1065.

U.S. Environmental Protection Agency. 2013. List of Designated Reference and Equivalent Methods. Available: http:// www.epa.gov/ttnamti1/files/ambient/criteria/referenceequivalent-methods-list.pdf [accessed 30 June 2013].

Vardas $\mathrm{PE}$, Kochiadakis GE, Manios EG, Kanoupakis EM, Zouridakis EG, Chlouverakis GI. 1996. Spectral analysis of heart rate variability before and during episodes of nocturnal ischaemia in patients with extensive coronary artery disease. Eur Heart J 17:388-393.

Verma V, Polidori A, Schauer JJ, Shafer MM, Cassee FR, Sioutas C. 2009. Redox activity of urban quasi-ultrafine particles from primary and secondary sources. Atmos Environ 43:6360-6368.

Zanobetti A, Gold DR, Stone PH, Suh HH, Schwartz J, Coull BA et al. 2010. Reduction in heart rate variability with traffic and air pollution in patients with coronary artery disease. Environ Health Perspect 118:324-330; doi:10.1289/ ehp.0901003. 